\title{
Stephen Petrina, Advanced Teaching Methods for the Technology Classroom
}

\author{
Information Science Publishing, Hershey, PA, 394 pp, \\ ISBN 1-59904338-6
}

\section{J. de Vries}

Received: 22 January 2007/ Accepted: 23 January 2007/

Published online: 20 February 2007

(C) Springer Science+Business Media B.V. 2007

Those who are acquainted with Steve Petrina's writing will perhaps be surprised to read the title of his latest book. For those of us who know his work, we know him to be one of those authors who are exceptionally good at pointing out all sorts of social and cultural biases in technology education practice. Petrina keeps us constantly aware by providing evidence for the often naïve way in which we think about teaching technology education and presenting a proper image of technology to young people. His criticisms always deal with the very basics of technology education. Given that perspective of Petrina's work, it may well come as a surprise that he has now authored a book that is as practical as a classroom teacher might wish a book on technology education to be. In this book he demonstrates an ability to transform his sharp critique on much of current technology education practice into down-to-earth guidelines on how to set up better classroom practices. In the end, of course, that is what counts. It is one thing to tell people what they are doing wrong, at least in certain aspects, but it is another thing to offer sensible guidance on better alternatives. This is what Petrina offers technology educators in this book.

The book is structured in three main sections: I. Analyzing and designing technology-based instruction, II. Analyzing and designing technology-based curriculum, and III. Implementing and evaluating curriculum and instruction. Two possible misunderstandings are dealt with in the Preface. The first concerns the term 'technology-based'. That term does not mean to suggest that the book is primarily about the use of technology for teaching. It does have that, but there is more. The book deals with teaching about technology (what it is), through technology (use of new technologies to support teaching) and for technology (functioning in a technological society). Secondly, the book is not meant to be a recipe book. Petrina immediately emphasizes the importance of 'reflective practice' (a term coined by Donald Schön). He makes it clear that good teaching practice requires that teachers

M. J. de Vries $(\bowtie)$

Faculty of Technology Management, Eindhoven University of Technology, P.O. Box 513, Eindhoven $5600 \mathrm{MB}$, The Netherlands

e-mail: M.J.d.Vries@tm.tue.nl 
continually think, and then rethink their practice rather than slavishly following page by page instructional books about how to teach.

Section I has five chapters. Chapter I deals with some basics in education: communication and planning. Here we find some classic taxonomies such as Bloom's, Krathwohl's and one for the psychomotor domain of which the origin is not mentioned (Hauenstein perhaps?). Chapter II deals with intelligence, different types of knowledge and types of reasoning. Sometimes the text and figures challenge the reader to question issues. In Figure 1, for example, Perina associates convergent reasoning with procedural knowledge and divergent reasoning with propositional knowledge. However, the accompanying text does not really clarify that and I wonder if it can really be argued for. Later he associates convergent reasoning with inductive reasoning and divergent reasoning with deductive reasoning (he calls them 'analogues'), and once again, I am not convinced that he makes a compelling argument for those premises. What I particularly do like in this chapter, however, is that he demonstrates that propositional knowledge is not just something that is expressed in words alone, but can also be expressed in drawings and schemes of work. Chapter III deals with issues that we know to be close to Petrina's heart, namely values and ethics. These issues need to become essential learning elements in technology education. Included in this paradigmatic framework must also be learning relating to the emotions that technology can evoke. For that reason Petrina also discusses the concept of 'emotional intelligence' in this chapter. Values are not just ethical values, and Petrina discussed quite a variety of them. A strong point made throughout this chapter, is that ethics cannot simply be just a matter of gut feelings or reactions, but rather that ethics can, and should be the subject of human reasoning.

It is not quite clear to me why Petrina also discussed skills (in general) in this chapter. As far as I am concerned it would have been quite justifiable for him to have a separate chapter for that topic.

Chapter IV introduces instructional methods and learning styles, and the relation between the two. In Chapter V we find creativity, design and problem solving skills discussed. This chapter is very up to date with respect to the design methods and tools that are dealt with, and I am sure many readers will find new and useful information in it.

Section II opens with Chapter VI on learning theory as applied to teaching about technology. Petrina discusses issues linking technology education to the idea of head, heart, hands and feet. He also discusses theories of experience by Dewey, Kolb and Dale, and dives headlong into several philosophical issues such as embodiment and determinism. Piaget and learning theory relating to constructivism also feature in this chapter, but significantly and importantly, so do more contemporary learning theories such as situated and distributed cognition.

Chapter VII helps technology teachers to make a case for technology education by offering ten justifications for teaching technology. Here too, I have some concerns about specific parts of the text. In Table 1 for example, Petrina offers an adapted version of Todd's taxonomy of technological literacy. Even in the adapted version I fail to see the rationale behind the order in which knowing what, that, how, when, why and why-not as the content of the various levels of literacy are introduced (the lowest level being only knowing what, the next level having more elements, etcetera). I expect that it is not difficult to find examples that contradict the order that is presented in the Table that summarizes that. Chapter VIII deals with content and 
standards of technology education. Unfortunately it is only the Standards for Technological Literacy, published by ITEA that are discussed. This serves to consequently narrow the philosophical debate to matters discussed in this one educational source. Perhaps the chapter would have been stronger if input from more recent philosophy of technology discussions had been used. Chapter IX deals with some curriculum and instruction design and theory. The structuring of a curriculum in modular form is dealt with for example.

Section III starts with a chapter on assessment and evaluation. That is certainly a problematic issue in technology education with its rich variety of activities. In particular design and project work are challenging in this respect and for that reason Petrina gives ample attention to the assessment of those activities. Finally there is Chapter XI on classroom management, facilities, design and safety. The title sound rather pragmatic but the chapter offers much more than just some practical guidelines. Petrina show that the importance of atmosphere in the classroom that should reflect certain values such as gender neutrality and fairness. The use of 'Humor' features as one of the sub-sections in this chapter. By the end of the chapter Petrina also gets practical and discusses different classroom set-ups together with budgetary issues.

The whole book is a nice balance between foundational and practical issues. It is quite an accomplishment to put together a comprehensive book such as this and the author is to be complimented for his work. I warmly recommend the book to teachers and teacher educators. 